\title{
\#Climate Change on TikTok: A Content Analysis of Videos
}

\author{
Corey H. Basch ${ }^{1}$ (D) B Bhavya Yalamanchili ${ }^{1}$. Joseph Fera ${ }^{2}$
}

Accepted: 29 August 2021 / Published online: 20 September 2021

(c) The Author(s), under exclusive licence to Springer Science+Business Media, LLC, part of Springer Nature 2021

\begin{abstract}
Current day youth have an important role in climate activism, as the decisions and policies made now will have long lasting impacts on the climate and sustainability. Climate change is becoming an increasing concern for younger generations. As such, the purpose of this study was to describe content related to climate change on TikTok. This study included 100 Englishlanguage videos related to climate change featured on TikTok. The hashtag \#climatechange was chosen because it had the most views of any related hashtag at the time of the study. The number of views, comments, and likes were recorded for each video. Each video was also observed for the presence of predetermined content characteristics. The 100 videos sampled collectively received 205,551,200 views, 40, 203,400 likes, and 666,089 comments. Only eight of the 100 videos included information from a reputable source. Only three of the characteristics were featured in a majority $(>50)$ of the videos. These were, presents climate change as real (93), affected populations (76), and climate anxiety/frustration (57). Videos mentioning natural disasters garnered 63,453,100 (30.87\%) views, 14,245,200 (35.43\%) likes, and 236,493 (35.50\%) comments. In all, 73 of the 100 videos mentioned at least one environmental impact. Videos including this theme earned 156,677,200 (76.22\%) views, 32,000,700 (79.60\%) likes, and 563,195 (84.55\%) comments. Social media platforms such as TikTok are important tools for understanding popular opinion regarding public health issues such as global climate change. However, the presence of credible professionals is essential on platforms such as TikTok to increase the chances that messaging is as comprehensive as time allows, while also being scientifically sound.
\end{abstract}

Keywords Climate change $\cdot$ Social media $\cdot$ TikTok

\section{Introduction}

Annually there are at least 150,000 deaths attributed to climate change globally [1]. There is consensus among climate scientists worldwide that there is an overall increase in global temperature due to the accumulation of greenhouse gases. Climate scientists predict worsening of climate change and associated health risks if not addressed [2]. Human impacts of industrialization and urbanization are largely responsible for the increase in global temperatures and these effects are potentially irreversible [3]. The effects of climate change are already being seen through the increased number of climate disruptions such as larger wildfires, longer drought periods,

Corey H. Basch

baschc@wpunj.edu

1 Department of Public Health, William Paterson University, University Hall, Wayne, NJ 07470, USA

2 Department of Mathematics, Lehman College, The City University of New York Bronx, New York City, NY, USA changes in weather patterns, increase in sea level, increased risk of flooding, and ice cap melting [2]. From 2000 to 2020, an annual average of 7.0 million acres burned due to wildfires. This is greater than double the acres burned annually from 1990 to 2000 (3.3 million acres) [4]. Arctic sea ice is declining at a rate of $13.1 \%$ per decade. As a result, from 1993 to present, sea levels have risen 3.3 millimeters per year [2]. Higher global temperatures impact different areas of the world differently. For example, a study assessing the impact of climate change in Great Lakes area indicated that climate change affected crop growing periods, thus lengthening pollen periods and allergy seasons [5]. Health risks resulting from climate change are also a large concern, as constant human impacts are deviations from equilibrium [6]. Contamination of air, groundwater, and soil, along with extreme climate disruptions negatively impact the health of local communities as well as industries like agriculture and infrastructure [5, 7-11]. A healthy planet is vital to health, peace, equality, and prosperity [12]. Disseminating information to inform the public about such issues is paramount. 
Social media usage has grown dramatically over the past 15 years and is very popular in the United States, with more than $70 \%$ of Americans using at least one platform [12]. These platforms are available for individuals of all ages, but certain age groups have higher usage than others for a given platform. Therefore, different social media platforms attract varied audiences of different ages and characteristics. Research indicates that $84 \%$ of American individuals aged 18-29 use at least one social media platform such as TikTok, YouTube, and/or Instagram [12]. Current day youth have an important role in climate activism, as the decisions and policies made now will have long lasting impacts on the climate and sustainability. Having constructive outlets for expression of dissent may reduce the risk of youth moving toward withdrawal, inaction, or anger directed toward other marginalized people such as economic migrants [13]. Increased activism and change in the future may be possible by having accessible climate change education available to youth through various sources including social media [14]. Social media platforms also have unlimited reach for obtaining knowledge, spreading awareness, as well as rallying support for movements, which has been seen through various other successful movements such as "March For Our Lives," which was youth lead [15]. Due to the widespread reach of the audience, social media platforms have been popular for discussing various health topics. A platform emerging in popularity is TikTok, which, as of August 2020, had over 2 billion app downloads globally [16]. The value of emerging social media platforms such as TikTok in disseminating public health information is beginning to be studied [17]. Public health officials and organizations have sought to use social media platforms and/or influencers from these platforms to spread awareness regarding important health topics, yet this is not the norm. An example of this is the Texas Department of State Health Services using social media influencers to spread awareness about COVID-19 to their followers [18]. Individuals aged 18-25 surveyed across 22 different countries indicated climate change as the most crucial issue the entire world was facing [19]. Climate change is becoming an increasing concern for younger generations [20]. As such, the purpose of this study was to describe content related to climate change on TikTok.

\section{Methods}

In total, this study included 100 English-language videos related to climate change featured on TikTok. The hashtag \#climatechange was chosen because it had the most views of any related hashtag at the time of the study at $653.7 \mathrm{M}$ views. The number of views, comments, and likes were recorded for each video. Each video was also observed for the presence of predetermined content characteristics, adapted from a prior study and a reliable fact sheet on climate change [2, 21]. One reviewer (BY) watched all 100 videos and recorded whether or not each of these content characteristics was present in that video. A second reviewer (CHB) observed 10 randomly selected videos (a 10\% sample) to determine inter rater-reliability. The two reviewers differed in only 2 data points resulting in high agreement $(\kappa=0.9932)$.

Microsoft Excel was used for all data entry, organization, and analysis. Descriptive statistics were performed and independent one-tailed $t$ tests $(\alpha=0.05)$ were run to determine if certain content themes had a statistical effect on the views, likes, and/or comments a video garnered. This study was exempt from review from the Institutional Review Board at William Paterson University as per their policy regarding studies that do not involve human subjects.

\section{Results}

The 100 videos sampled collectively received 205,551,200 views, 40, 203,400 likes, and 666,089 comments. The average (standard deviation) number of likes, views, and comments for these videos were as follows: $2,055,512$ $(3,823,946.33), 402,034(704,685.73)$, and 6,661 $(16,806.70)$.

Table 1 shows the content characteristics considered for this study. One characteristic, mentions hurricanes, was not present in any of the videos and was omitted from the table. This table indicates how many of the videos featured a content characteristic along with view, likes, and comment information. Percentages are also included for comparison purposes. Only eight of the 100 videos included information from a reputable source such as the United States Environmental Protection Agency, public health professional, environmentalists, etc. Videos including reputable sources gained 25,227,400 (12.27\%) views, 4,266,000 (10.61\%) likes, and 44,711 (6.71\%) comments.

Only 3 of the characteristics were featured in a majority $(>50)$ of the videos. These were, presents climate change as real (93), affected populations (76), and climate anxiety/ frustration (57). Respectively, videos featuring these content areas accounted for $87.85 \%, 73.91 \%$, and $53.66 \%$ of the over $205 \mathrm{M}$ total views. Fewer than 5\% of the sample praised government policy/leaders, praised brands/companies, had misinformation, misinterpreted weather patterns with climate change, presented climate change as fake, and mentioned tornadoes. Videos featuring this content received fewer than $3 \%$ of the total views, except for videos featuring misinformation which garnered over $13 \mathrm{M}$ views (6.45\%).

All 100 videos were observed for the mentioning of natural disasters. The natural disasters considered were wildfires, drought/heat wave, hurricanes, and tornadoes. Collectively, 23 of the 100 videos mentioned at least one natural disaster. Videos incorporating this theme garnered 63,453,100 
Table 1 Observed characteristics, content, views, likes, and comments of 100 climate change TikTok videos

\begin{tabular}{|c|c|c|c|c|c|c|c|}
\hline & $\mathrm{N}$ & Views & $\%$ & Likes & $\%$ & Comments & $\%$ \\
\hline & 100 & $205,551,200$ & 100 & $40,203,400$ & 100 & 666,089 & 100 \\
\hline Presents climate change as real & 93 & $180,568,700$ & 87.85 & $37,317,700$ & 92.82 & 639,217 & 95.97 \\
\hline Affected populations & 76 & $151,926,300$ & 73.91 & $30,635,100$ & 76.20 & 542,408 & 81.43 \\
\hline Climate anxiety/frustration & 57 & $110,300,700$ & 53.66 & $24,026,200$ & 59.76 & 410,243 & 61.59 \\
\hline Mentions health impacts & 49 & $110,332,100$ & 53.68 & $23,689,200$ & 58.92 & 432,098 & 64.87 \\
\hline Pollution & 49 & $98,873,900$ & 48.10 & $20,841,900$ & 51.84 & 313,957 & 47.13 \\
\hline Environmental impacts: animals & 45 & $95,992,800$ & 46.70 & $21,444,700$ & 53.34 & 413996 & 62.15 \\
\hline Mentions future generations & 38 & $82,442,800$ & 40.11 & $16,994,800$ & 42.27 & 268,978 & 40.38 \\
\hline Environmental impacts: global temperature levels & 36 & $105,830,000$ & 51.49 & $21,991,600$ & 54.70 & 411,307 & 61.75 \\
\hline Mentions environmental justice & 34 & $76,736,300$ & 37.33 & $17,302,900$ & 43.04 & 282,739 & 42.45 \\
\hline Environmental impacts: arctic Ice Caps/Sheets & 32 & $87,716,000$ & 42.67 & $19,122,900$ & 47.57 & 405,746 & 60.91 \\
\hline Environmental impacts: crops/plants & 32 & $74,834,400$ & 36.41 & $14,152,600$ & 35.20 & 259708 & 38.99 \\
\hline Advocacy/charity & 26 & $29,075,400$ & 14.15 & $7,179,800$ & 17.86 & 141,968 & 21.31 \\
\hline Environmental impacts: ocean/sea levels & 25 & $75,624,200$ & 36.79 & $14,739,700$ & 36.66 & 308,205 & 46.27 \\
\hline Criticizes government policy/leaders & 22 & $66,713,700$ & 32.46 & $14,814,200$ & 36.85 & 247181 & 37.11 \\
\hline Criticizes brands/companies & 22 & $65,464,700$ & 31.85 & $13,708,700$ & 34.10 & 222689 & 33.43 \\
\hline Mentions natural disasters: wild fires & 20 & $58,148,800$ & 28.29 & $13,155,900$ & 32.72 & 228,074 & 34.24 \\
\hline $\begin{array}{l}\text { Displays steps to reduce carbon footprint/environmental impact: micro } \\
\text { level }\end{array}$ & 19 & $27,413,000$ & 13.34 & $4,661,600$ & 11.60 & 34,432 & 5.17 \\
\hline Environmental impacts: greenhouse gases & 14 & $51,242,700$ & 24.93 & $11,903,300$ & 29.61 & 203295 & 30.52 \\
\hline Mentions health disparities & 12 & $13,390,400$ & 6.51 & $3,173,400$ & 7.89 & 39,609 & 5.95 \\
\hline Environmental impacts: carbon dioxide & 12 & $9,442,800$ & 4.59 & $2,556,200$ & 6.36 & 35,266 & 5.29 \\
\hline Mentions natural disasters: drought/heat wave & 9 & $16,263,300$ & 7.91 & $3,430,800$ & 8.53 & 35,954 & 5.40 \\
\hline Reputable source: EPA, public health professional, environmentalist & 8 & $25,227,400$ & 12.27 & $4,266,000$ & 10.61 & 44711 & 6.71 \\
\hline Policy recommendations: macro level & 8 & $12,585,100$ & 6.12 & $2,867,100$ & 7.13 & 58,065 & 8.72 \\
\hline Praises government policy/leaders & 4 & $2,093,800$ & 1.02 & 638,200 & 1.59 & 11040 & 1.66 \\
\hline Praises brands/companies & 4 & $4,646,100$ & 2.26 & 696,600 & 1.73 & 4960 & 0.74 \\
\hline Has misinformation & 4 & $13,259,200$ & 6.45 & $2,001,400$ & 4.98 & 28,631 & 4.30 \\
\hline Misinterpreting weather patterns with climate change & 2 & $2,300,000$ & 1.12 & 300,400 & 0.75 & 3467 & 0.52 \\
\hline Presents climate change as fake & 2 & $2,059,200$ & 1.00 & 460,300 & 1.14 & 3179 & 0.48 \\
\hline Mentions natural disasters: tornadoes & 1 & $2,000,000$ & 0.97 & 191,100 & 0.48 & 698 & 0.10 \\
\hline
\end{tabular}

$(30.87 \%)$ views, $14,245,200(35.43 \%)$ likes, and 236,493 $(35.50 \%)$ comments. Independent one-tailed t-tests $(\alpha=$ 0.05 ) indicated that mentioning natural disasters had a statistical effect on the average number of likes received by a video $(\mathrm{p}=0.0460)$. The average (standard deviation) number of likes received by a video featuring natural disasters was 619,356.52 $(1,359,935.25)$; the average (standard deviation) number of likes received by a video without this content was 337,119.48 (304,863.04). There was no statistical effect observed for featuring natural disasters on a video's views $(p=0.1586)$ or comments $(p=0.1204)$. See Table 2 for full details.

All 100 videos were also observed for the mentioning of environmental impacts. The environmental impacts considered were global temperature levels, carbon dioxide, sea/ocean levels, arctic ice caps/sheets, greenhouse gases, animals, and crops/plants. In all, 73 of the 100 videos mentioned at least one environmental impact. Videos including this theme earned 156,677,200 (76.22\%) views, $32,000,700(79.60 \%)$ likes, and 563,195 (84.55\%) comments. Independent one-tailed $t$ tests $(\alpha=0.05)$ showed that the inclusion of environmental impacts did not have a statistical effect on the average number of views $(p=0.3492)$, likes $(\mathrm{p}=0.1997)$, or comments $(\mathrm{p}=0.1524)$ received by a video. See Table 2 for full details.

\section{Discussion}

The findings from this study indicate that climate change is being represented on TikTok as a legitimate and anxiety provoking issue. A few of the videos included in this sample are misinformative, but the few that were included garnered millions of views. Many videos featured natural disasters and at least one of the many impacts of global climate change on 
Table 2 Average views, likes, and comments for videos featuring vs. not featuring natural disasters and environmental impacts along with resulting $p$ values from independent one-tailed t-tests.

\begin{tabular}{|c|c|c|c|c|}
\hline & \multicolumn{2}{|c|}{ Includes natural disasters } & \multicolumn{2}{|c|}{ Includes environmental impacts } \\
\hline & Yes & No & Yes & No \\
\hline \multicolumn{5}{|l|}{ Views } \\
\hline Average & $2,758,830.43$ & $1,845,429.87$ & $2,146,263.01$ & $1,810,148.15$ \\
\hline St Dev & $7,179,368.70$ & $1,983,169.83$ & $4,283,256.17$ & $2,188,034.60$ \\
\hline $\mathrm{p}$ value & 0.158 & & 0.349 & \\
\hline \multicolumn{5}{|l|}{ Likes } \\
\hline Average & $619,356.52$ & $337,119.48$ & $438,365.75$ & $303,803.70$ \\
\hline St Dev & $1,359,935.25$ & $304,863.04$ & $812,963.99$ & $216,544.21$ \\
\hline $\mathrm{p}$ value & 0.0460 & & 0.199 & \\
\hline \multicolumn{5}{|l|}{ Comments } \\
\hline Average & $10,282.30$ & $5,579.17$ & $7,715.00$ & $3,810.89$ \\
\hline St Dev & $31,736.99$ & $8,439.51$ & $19,369.26$ & $5,005.88$ \\
\hline $\mathrm{p}$ value & 0.120 & & 0.152 & \\
\hline
\end{tabular}

the environment. However, few videos represented comprehensive coverage of information. Collectively, these findings suggest that public and environmental health professionals should be aware of both the benefits and dangers of using such platforms for information dissemination. This is consistent with a study of affective themes on TikTok in which authors found that, "non- experts, including adolescents and early adults, leverage TikTok's affordances to express their concern, frustrations, and personal stake in what they perceive to be salient issues of their time." [22]. The limitations of this study include the small sample size and the restriction to English-language videos. While there were only 100 videos included in this study, they represented roughly $32 \%$ of the cumulative views of the hashtag at the time the study took place. Content on TikTok is being updated and on a daily basis, and therefore, is limited by a cross-sectional approach. Regardless of these limitations, this is among the first studies that examine the content of TikTok videos related to global climate change.

Information regarding climate change is often obtained by individuals through both traditional sources like television and non-traditional sources like social media platforms. Non-traditional news sources are most commonly used by individuals aged 18-24. This age group accesses non-traditional sources of climate change information from social media 3 times as often as those aged over 55 years [22]. As climate change is a polarizing topic, there is a lot of varying information regarding climate change on media platforms. The impact of factual global climate change information acquired via media sources depends on an individual's media literacy, ability to separate facts from fiction, and assessing political claims and decisions [23]. Social media posts and views can be indicative of general thought and behaviors [24]. This is likely due to the fact that social media platforms are free, relatively accessible, and have few restrictions regarding the content [22].
A barrier to taking action is the lack of basic knowledge, inconsistent attention to climate change and inefficient messaging prevents, which can prevent social media platforms from being effective in promoting behavioral change. Media tend to frame climate change strictly as an environmental issue. Instead, health risks associated with climate change may be more effectively communicated by framing them as public health threat and supplemented with expert guidance [25-28]. Trust and distrust regarding climate change information depends on those providing the information [29, 30]. Thus, social media platforms such as TikTok are important tools for understanding popular opinion regarding public health issues such as global climate change. However, the presence of credible professionals is essential on platforms such as TikTok to increase the chances that messaging is as comprehensive as time allows, while also being scientifically sound.

Authors Contributions $\mathrm{CHB}$ and BY conceptualized the study. BY collected the data, JF conducted the data analysis. All authors contributed to the manuscript production.

Funding This study received no funding.

\section{Declarations}

Conflict of interest The authors declare that they have no conflict of interest.

Ethical Approval This study was exempt from review from the Institutional Review Board at William Paterson University as per their policy regarding studies that do not involve human subjects. 


\section{References}

1. World Health Organization. (2021). Climate change. World Health Organization. https://www.who.int/heli/risks/climate/climatecha nge/en/.

2. NASA. (n.d.). Climate change: Vital signs of the planet. NASA. https://climate.nasa.gov/.

3. United Nations. (n.d.). Climate change. United Nations. https:// www.un.org/en/global-issues/climate-change.

4. Congressional Research Service. (2021). Wildfire statistics. Federation of American Scientists. https://fas.org/sgp/crs/misc/IF102 44.pdf.

5. U.S. Global Change Research Program. (n.d.). Impacts on society. GlobalChange.gov. https://www.globalchange.gov/climatechange/impacts-society.

6. Butler, C. D. (2018). Climate change, health and existential risks to civilization: A comprehensive review (1989-2013). International Journal of Environmental Research and Public Health, 15(10), 2266. https://doi.org/10.3390/ijerph15102266

7. Patz, J. A., Vavrus, S. J., Uejio, C. K., \& McLellan, S. L. (2008). Climate change and waterborne disease risk in the Great Lakes region of the U.S. American Journal of Preventive Medicine, 35(5), 451-458. https://doi.org/10.1016/j.amepre.2008.08.026

8. Sampson, N. R., Gronlund, C. J., Buxton, M. A., et al. (2013). Staying cool in a changing climate: Reaching vulnerable populations during heat events. Global Environmental Change., 23(2), 475-484. https://doi.org/10.1016/j.gloenvcha.2012.12.011

9. Patz, J. A., McGeehin, M. A., Bernard, S. M., et al. (2000). The potential health impacts of climate variability and change for the United States: Executive summary of the report of the health sector of the U.S national assessment. Environmental Health Perspectives, 108(4), 367-376. https://doi.org/10.1289/ehp.00108367

10. Ebi, K. L., Mills, D. M., Smith, J. B., \& Grambsch, A. (2006). Climate change and human health impacts in the United States: An update on the results of the U.S. national assessment. Environmental Health Perspectives., 114(9), 1318-1324. https://doi. org/10.1289/ehp. 8880

11. United Nations. (2021). Key findings. United Nations. https:// www.un.org/en/climatechange/science/key-findings.

12. Pew Research Center. (2021). Demographics of social media users and adoption in the United States. Pew Research Center: Internet, Science \& Tech. https://www.pewresearch.org/internet/fact-sheet/ social-media/?menuItem $=3814$ afe3-3f3c-4623-910b-8a6a37885a b8.

13. O'brien, K., Selboe, E., \& Hayward, B. M. (2018). Exploring youth activism on climate change. Ecology and Society, 23(3).

14. Han, H., \& Ahn, S. W. (2020). Youth mobilization to stop global climate change: Narratives and impact. Sustainability, 12(10), 4127.

15. Bandura, A., \& Cherry, L. (2020). Enlisting the power of youth for climate change. American Psychologist, 75(7), 945-951. https:// doi.org/10.1037/amp0000512

16. Sherman, A. (2020). TikTok reveals detailed user numbers for the first time. CNBC. https://www.cnbc.com/2020/08/24/tiktok-revea ls-us-global-user-growth-numbers-for-first-time.htm.
17. Basch, C. H., Meleo-Erwin, Z., Fera, J., Jaime, C., \& Basch, C. E. (2021). A global pandemic in the time of viral memes: COVID19 vaccine misinformation and disinformation on TikTok. Human Vaccines \& Immunotherapeutics, 1-5. Advance online publication.

18. Marks, M. (2020). How state officials are trying to use TikTok to stop the spread Of COVID-19. Texas Standard. https://www.texasstandard.org/stories/how-state-offic ials-are-trying-to-use-tiktok-to-stop-the-spread-of-covid-19/.

19. Barbiroglio, E. (2019). Generation Z fears climate change more than anything else. Forbes. https://www.forbes.com/sites/emanu elabarbiroglio/2019/12/09/generation-z-fears-climate-changemore-than-anything-else/?sh=4ce58937501b.

20. United Nations. (n.d.). Youth in action. United Nations. https:// www.un.org/en/climatechange/youth-in-action.

21. Duran-Becerra, B., Hillyer, G. C., Cosgrove, A., \& Basch, C. H. (2020). Climate change on YouTube: A potential platform for youth learning. Health Promotion Perspectives., 10(3), 282-286.

22. Hautea, S., Parks, P., Takahashi, B., Zeng, J. (2021). Showing they care (or don't): Affective publics and ambivalent climate activism on TikTok. Social Media and Society. 1-14.

23. And1, S. (2020). How people access news about climate change. Reuters Institute Digital News Report. https://www.digitalnew sreport.org/survey/2020/how-people-access-news-about-clima te-change/.

24. Loy, L. S., Hamann, K. R., \& Reese, G. (2020). Navigating through the jungle of information. Informational self-efficacy predicts climate change-related media exposure, knowledge, and behaviour. Climatic Change, 1-20.

25. Signorini, A. (2014). Use of social media to monitor and predict outbreaks and public opinion on health topics.

26. Depoux, A., Hémono, M., Puig-Malet, S., Pédron, R., \& Flahault, A. (2017). Communicating climate change and health in the media. Public Health Reviews, 38(1), 1-4.

27. Maibach, E. W., Nisbet, M., Baldwin, P., Akerlof, K., \& Diao, G. (2010). Reframing climate change as a public health issue: An exploratory study of public reactions. BMC Public Health, 1(10), 299. https://doi.org/10.1186/1471-2458-10-299

28. Sanderson, M., Doyle, H., \& Walsh, P. (2020). Developing and implementing a targeted health-focused climate communications campaign in Ontario-\#MakeItBetter. Canadian Journal of Public Health, 111(6), 869-875. https://doi.org/10.17269/ s41997-020-00352-z

29. Walter, S., Lörcher, I., \& Brüggemann, M. (2019). Scientific networks on Twitter: Analyzing scientists' interactions in the climate change debate. Public Understanding of Science, 28(6), 696-712. https://doi.org/10.1177/0963662519844131

30. Buys, L., Aird, R., van Megen, K., Miller, E., \& Sommerfield, J. (2014). Perceptions of climate change and trust providers in rural Australia. Public Understanding of Science, 23(2), 170-188.

Publisher's Note Springer Nature remains neutral with regard to jurisdictional claims in published maps and institutional affiliations. 